\title{
The Influence of Government Behavior on the Development of Hainan's Lodging Industry
}

\author{
Yifei Tao \\ Hainan University, Hainan Haikou, 570100
}

Keywords: government behavior; Hainan B\&B; influence

\begin{abstract}
At this stage, China attaches great importance to the characteristics of leisure time and lays a good foundation for promoting the development of the hotel industry. The housing industry reflects new developments in some areas. Different theme homes adapt to the multi-level needs of the society. Diversified investment entities and business methods provide the impetus for the growth of the hotel industry. With its beautiful pastoral scenery and unique ethnic customs, Hainan Province has great potential for development. Local governments must fully reflect the leadership role and further enhance their management capabilities to promote the healthy development of Hainan B\&B.
\end{abstract}

\section{Introduction}

"B\&B" is a tourist accommodation method that originated in Europe in the middle of the last century and is popular in Japan. Foreign experts pointed out that the concept of the B\&B is that the villagers rent out their own unoccupied rooms to the passengers so that they can experience the rural life and be close to nature. It is a particularly strong rural atmosphere. On February 27, 2018, the Hainan Provincial People's Government promulgated the "Guiding Opinions of the Hainan Provincial People's Government on Promoting the Development of Rural B\&Bs", which pointed out that it is necessary to give priority to development of introduction of beautiful rural demonstration villages, traditional villages, scenic villages, historical and cultural famous towns, etc. Gradually, guiding the sustainable and healthy development of Hainan Province's country houses.

\section{Development characteristics of hainan $b \& b$}

\subsection{Stable development of theme house}

B\&Bs with different themes can provide visitors with differentiated experiential services. Haikou Haikou has established a variety of experiential B\&Bs in the vast rural areas. These B\&Bs are themed B\&Bs that come with the help of scenic spots. For example, the Pear House is a place where visitors can enjoy Boao Water City, visit ecological farms, watch fishing boats and seagulls and ebb and flow.

\subsection{Rapidly developing creative homestay}

Different types of creative homestays fit the needs of multiculturalism. The management schemes implemented by the managers and operators of the property industry in various regions reflect their own characteristics. Some people establish European-style homestays to meet the requirements of couples; some have established art homestays to meet the requirements of young artists; The style of the resort, the resort style, etc. all reflect the creativity of the operator.

\subsection{Diversified investment and business investment entities}

Different types of investment and business entities promote the continuous and rapid development of the hotel industry. There are four main types of investment and business entities in the property. The first is that the farmer operates the homestay independently, the second is the farmer and the company jointly operate the $B \& B$, the third is the private investment in the $B \& B$, and the fourth is the $B \& B$ Entrusted to flow to others to operate. These four types of bed and 
breakfast business models are combined with each other to form a stable pattern of stable development of the hotel industry.

\section{The favorable conditions of Hainan B\&B development}

\subsection{Rich in resources}

First of all, diverse ecological resources. Hainan province is rich in natural resources. It has a forest coverage rate of 51.5\% in the South China Sea. It has the highest visibility of Yalong Bay and its Yanoda Rainforest. It has the only green forest and tropical mangroves in China. With the help of sea, beach, sunshine, mountain, forest and other resources, Hainan has become the most developed province in China.

Second, it has a wealth of human resources. Hainan is a multi-cultural, multi-ethnic province and is a gathering place for Miao and Li nationalities. There are military festivals such as the Junpo Festival and the Miao nationality "March 3". There are craft cultures such as pottery, carving, printing and dyeing and preparation of the Miao nationality. There are food cultures such as the Miao people's sour food, the Li tri-color rice, the mountain wine, and the bamboo rice. Hainan's special humanistic environment effectively guarantees the development of the hotel. By operating the different theme of the hotel, visitors can fully appreciate the local folk culture and residence culture.

\subsection{Strong atmosphere}

Hainan's rural areas are distributed with nearly seven layers of tourism resources and nearly six layers of population. The unique rural scenery, ethnic customs and local culture can effectively promote the development of rural tourism. At the end of the last century, Hainan has aroused the upsurge of rural tourism and launched some tourism products that mainly experience rural life and enjoy the natural scenery, such as Yujiale, Tropical Botanical Garden, Wanjia Orchard and Green Maple Farm. In September 2000, Hainan launched an activity to build a civilized ecological village to guide the development of Hainan rural tourism to the development of points, films and lines. The continuous and rapid development of Hainan's rural tourism promotes rural construction and more accommodation facilities, laying a good foundation for the emergence of the country house. The villagers gradually and consciously and purposefully changed their houses into homestays and promoted the country house.

The emergence and development.

\subsection{Policy support}

China's Ministry of Agriculture issued a notice to promote the development of leisure agriculture, guiding and advocating farmers to carry out tourism business activities with their own homes. The Tourism Development Committee of Hainan Province introduced the "Country Tourism Master Plan” from 2014 to 2020 and proposed the seven-year rural tourism development plan of the province, expounding that the future rural tourism will be the channel for Hainan cultural and social development and rural economic development, while rural tourism is inseparable from the continued development of the $B \& B$, especially the country house. At this stage, typical B\&Bs in Hainan include: Xiongchun Village B\&B in Hongmao Town, "Nanyang Brothers" B\&B and "Pear House" B\&B. The local government pays special attention to the development of the country house, and actively promotes "the most beautiful towns" and "the most beautiful villages" through Weibo and WeChat, attracting more people to know the $\mathrm{B} \& \mathrm{~B}$, entering the $\mathrm{B} \& \mathrm{~B}$ and promoting the $\mathrm{B} \& \mathrm{~B}$.

\section{The influence of government behavior on the development of Hainan homestay}

\subsection{To formulate management regulations and realize the legalization of supervision}

In order to promote the sustainable development of Hainan home stay industry, we should attach importance to the top-level design and realize the legal regulation.At the present stage of the rapid 
development of Hainan's home stay industry, local governments should supplement and revise the tourism regulations, which can add home stay facilities into the regulations, laying the foundation for the lower government to elaborate the regulations and formulate a targeted management method for residents' dormitory managers. "Measures for the management of residents' dormitories" implemented by local governments needs to specify home stay facility operation qualifications, nature of business, management organization, opening conditions, service content, etc., especially in the aspect of scale control and the traditional sense of the hotel, lays a institutional foundation for the legality of hainan home stay facility in environmental protection, health and fire control. When foreign countries promote rural tourism, the government attaches great importance to legislation. Foreign laws and regulations on the safety of homestay, ecological and environmental protection, land and housing rental price, business scale, application for organization or individual conditions, etc., lay the foundation for the development of homestay tourism. The administrative regulations of home stay in China not only guarantee the health and standard development of home stay industry from the legal level, but also clearly stipulate the personal insurance of residents and the property safety of operators so as to actively protect the interests of all parties.

\subsection{Macroscopical plan, establish sound examine and approve mechanism}

In the process of guiding the development of home stay facilities, governments at all levels of Hainan province should establish a comprehensive plan for home stay facilities, which should be included in the development plan of cities and towns and the overall plan of tourism. Combined with the planning, the spatial clustering effect of the home stay industry will be generated, and the unsafe areas that may appear will be removed from the planning, so that the approval of home stay can meet the relevant requirements of the planning. The measures for the management of dormitory keepers issued by Hainan local government clearly stipulates the number and nature of rooms for home stay.When carrying out administrative examination and approval, the government should prevent any contradiction or mutual conditions in the examination and approval process. We should reduce the approval process, actively build the official website of home stay, open the approval process on the network platform, and provide one-stop service for examination and approval. The government can publish information related to homestay on this website. Under the circumstance that the industry association of homestay has not developed comprehensively at the present stage, the official website can issue the relevant system to evaluate the rating of homestay, evaluate the rating of homestay through its authority, and establish the validity period of various grades. Efforts should be made to ensure the fairness, transparency and openness of the selection, so as to stimulate the initiative and enthusiasm of the operators of home stay facilities to the greatest extent, effectively guide the tourists and promote the sustainable, stable and healthy development of home stay facilities.

\subsection{Establishing public supporting facilities in rural areas}

When designing and planning a home stay facility, the government should strengthen the external environment for the economic development of the home stay facility and actively improve the vegetation, water quality and air in the countryside according to the requirements of the construction of central villages and towns, new rural areas and ecological construction. In addition, in terms of public finance, we should increase investment in home stay facilities, actively raise social capital, and constantly improve infrastructure facilities in rural areas. Actively renovate and expand the existing infrastructure of home stay facilities, such as comprehensive coverage of communication signals, construction of sewage discharge system, renovation of water and electricity pipeline network, establishment of home stay and public places signs, construction of parking lots, widening and renovation of roads, etc. Culture factor is important connotation of home stay facility industry, Hainan government departments should attach importance to the perimeter of the home stay facility, the humanities environment construction of ancient buildings and historical and cultural protection according to the different regions of rural spiritual civilization construction, dig deeper into the local folk culture, explore the effective carrier of reflect local conditions and customs, promote the sustained economic steady development to establish the cultural atmosphere 
of home stay facility, at the same time enhance the local farmers' comprehensive ability and humanistic quality.

\section{Conclusion}

At present, China enjoys social stability and sustained economic development, the people are more active in in-depth tourism and national tourism, which is bound to promote the development of the home stay industry. In this process, some problems inevitably arise in the development of home stay facility, and the problems to be dealt with need to be constantly analyzed and summarized. The government is an important force, and the Hainan government departments should formulate management regulations to realize the legalization of supervision. We should make macro plans and establish a sound examination and approval mechanism. We will establish public supporting facilities in rural areas to promote the healthy and stable development of the local home stay industry.

\section{References}

[1] Zhu Yueliang. Opportunities and challenges of rural tourism home stay industry under the background of sharing economy[J]. Agricultural Economy, 2018(07):113-115.

[2] Qu Yanhui. Analysis on the development of hot spring home stay industry in Shuangtai town, Yingkou city[J]. China Collective Economy, 2018(09):12-13.

[3] Li Hongbao and Wen Fangqin. Development and improvement strategies of the home stay industry in south Jiangsu under the background of supply-side reform[J]. China Market, 2018(04):287-288.

[4] Li Ze. Research on the sustainable development mechanism of Hubin home stay industry [D]. Yunnan Normal University, 2017.

[5] Niutianjiao. Research on development status and strategies of home stay industry in Hebei province[J]. Tourism Overview (second half), 2017(05):11-12. 